\title{
SARCOMA OF THE HEART IN A CHILD
}

\author{
BY \\ E. G. G. ROBERTS and R. M. E. SEAL \\ From the Departments of Child Health and Pathology, Welsh National School of Medicine
}

(Received for Publication December 6, 1950)

Malignant heart tumours are rare, and seldom diagnosed during life; such a diagnosis is particularly difficult in childhood. Mahaim (1945), in a comprehensive review of over 400 heart tumours, found 87 primary sarcomas, only five of which occurred in children under 15 years. Lisa, Hirschhorn, and Hart (1941), reviewing the literature, found 30 reported cases of secondary tumour involvement of the heart with only two examples of sarcoma in childhood.

This case is reported principally on account of the unusual presentation and because of the difficulty in making a clinical diagnosis. The prospects of successful cardiac surgery (Beck, 1942) now cause clinical diagnosis to be of more than academic interest.

\section{Case Report}

T.W., a boy of 3 years, complained of sudden pain in the right hip joint, associated with fever and general malaise. A radiograph of the pelvis taken a week after the onset seemed normal, but he was treated intensively with systemic penicillin on the assumption that his condition might be acute osteomyelitis. The fever subsided after four days, but because of a limp and a rapid general deterioration during this period he was admitted to hospital. The history revealed that the milestones of development had been greatly delayed, and that recently he had exhibited choreiform movements with a tendency to fall.

The child was pale and wasted, making grunting noises, and displaying involuntary movements of hands and face. The temperature was $100^{\circ} \mathrm{F}$., the pulse 150 per minute, and respiration 35 per minute.

He seemed in obvious pain, though the site was difficult to determine because of his mental backwardness. The right hip joint movements were all limited and painful in extreme ranges, but there was no localized bony tenderness. The fundi were normal, and there were no neurological signs, apart from the choreiform movements.

He had a regular pulse, persistently over 130 per minute. The blood pressure was $105 / 70 \mathrm{~mm}$. Hg. The neck veins were prominent. An apex beat in the fifth left space 4 in. from the mid-sternal line was localized, and dyspnoea was easily induced. The heart sounds were faint, but a soft apical systolic murmur was detected. An E.C.G. showed right ventricular preponderance and no evidence of heart block. Cardioscopy indicated general heart enlargement only, and a chest radiograph did not suggest lung pathology in this initial phase. The blood count was normal and repeated blood cultures were negative.

A radiograph of the pelvis now showed extensive erosion of the right iliac and pubic bones, as well as of the upper ends of both femora. The E.S.R. was $50 \mathrm{~mm}$./hr. and the Mantoux reaction (1/100) negative.

Treatment with penicillin, aspirin, and phenobarbitone did not influence the fever or the rapidly deteriorating clinical condition, and three weeks after admission he developed facial oedema, cyanosis, congested neck veins and a basal pericardial friction rub. The liver could be felt two fingers' breadth below the right costal margin; coarse rhonchi were audible over both lungs. A radiograph of the chest three days before death showed generalized lung mottling with a distorted right heart shadow. Breathing became embarrassed, and cyanosis deepened before death, five weeks after the onset of symptoms.

Differential Diagnosis. When the boy was first seen it seemed possible that this might be a case of rheumatic chorea with carditis, complicated by osteomyelitis. The involuntary movements, tachycardia, and uncontrollable fever with hip pain favoured this impression, but his mental state made it difficult to get a clear picture.

The discovery of disseminated bone lesions made us entertain the possibility of Bact. coli endocarditis with migrating osteomyelitis, though this was difficult to correlate with the other findings.

When superior vena caval block and generalized mottling of the lung fields became evident terminally, sarcomatosis with a mediastinal deposit was postulated. The cardiac signs might then be explained by neoplastic involvement, though the improbability of heart tumour at this age made us tentatively venture the diagnosis of rheumatic chorea and pancarditis, with osteomyelitis and terminal thrombosis of the superior vena cava.

Necropsy Findings. Externally the body was as described above. The heart was enlarged (weight, $210 \mathrm{~g}$.), and the pericardium contained about $10 \mathrm{oz}$. of coloured fluid. There was a large tumour measuring $5 \times 4.5 \times 5 \mathrm{~cm}$. in the position of the inter-auricular septum, almost filling the left auricle and obstructing the mitral valve orifice. It also bulged into the right auricle, particularly superiorly, and compressed the superior vena cava as it entered the auricle (Fig. 1).

The aorta, and to a less extent the pulmonary artery, were also compressed by the growth. It was covered by 


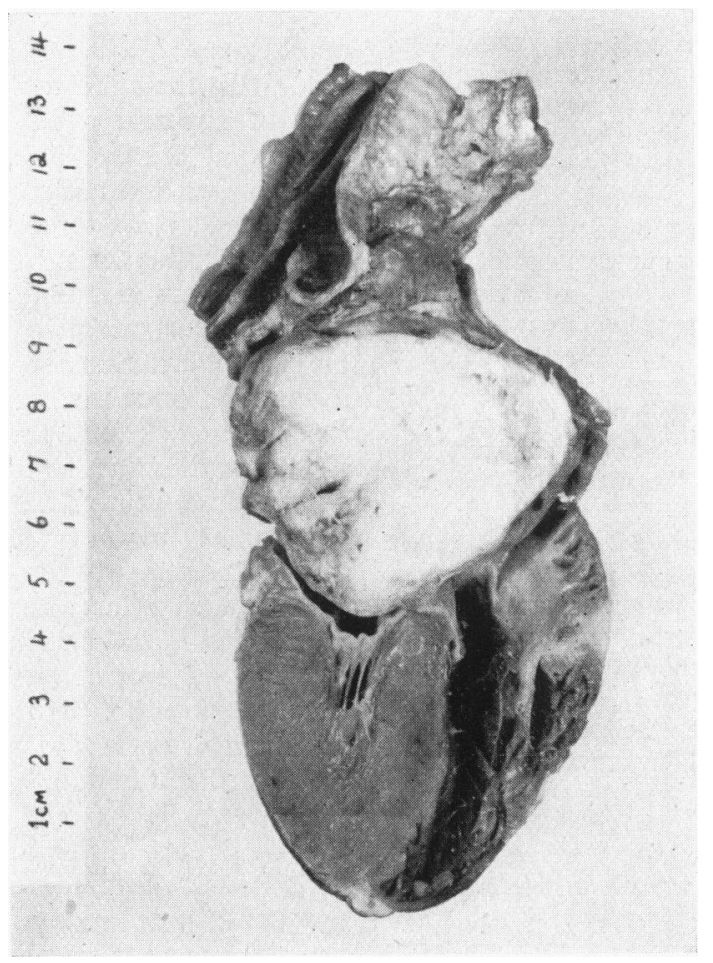

FIG. 1. Coronal section of heart showing tumour filling both auricles and compressing superior vena cava.

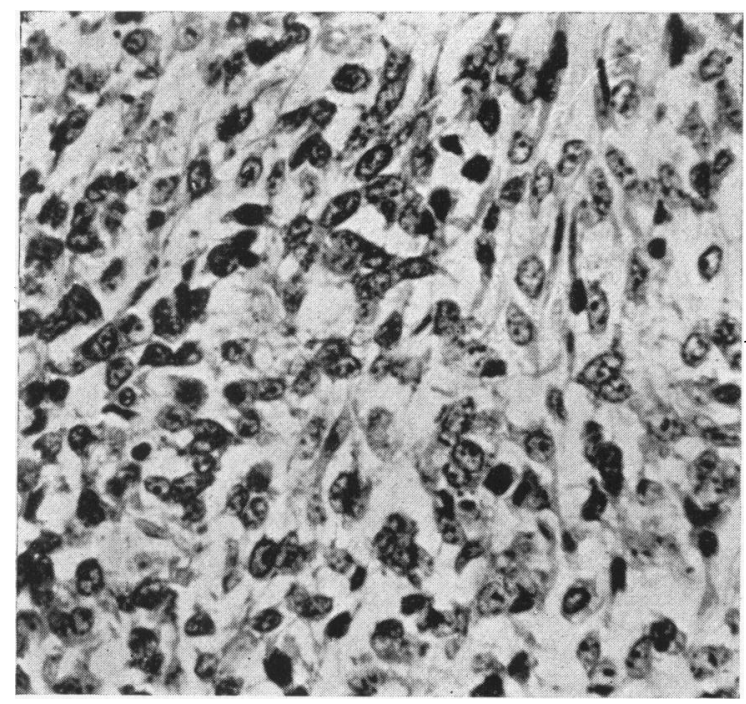

FIG. 2.-Photomicrograph showing structure of heart tumour (haematoxylin and eosin. $\times 380$ ).

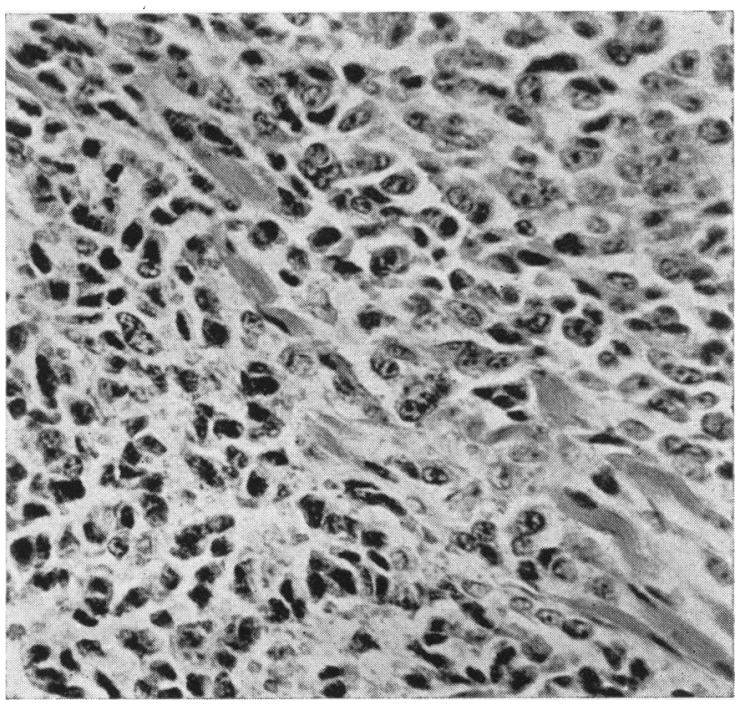

Fig. 3.-Photomicrograph showing infiltration of gluteus muscle by tumour of right ilium (haematoxylin and eosin. $\times 360$ ) 
endocardium except at its widest part, where the surface was roughened with loss of endothelial covering. The cut surface of the tumour showed it to be homogeneous and white. There was a tumour deposit about $1.5 \mathrm{~cm}$. in diameter in the wall of the left ventricle posteriorly and numerous small nodules on the aorta and pulmonary artery.

Each pleural cavity contained about 20-30 oz. of straw-coloured fluid. There were numerous pale tumour nodules (varying from $1 \mathrm{~mm}$. to $1 \mathrm{~cm}$. in diameter) on the pleural surfaces of both lungs giving them a striking resemblance to a 'hobnailed' liver. The cut surface showed similar nodules scattered uniformly throughout the lung substance. The right lobe of the liver contained a few pale tumour deposits, and there was a solitary nodule $0.75 \mathrm{~cm}$. in diameter in the cortex of the right kidney.

White tumour tissue was found in the head of the left femur and the right ilium. The right gluteus externally, and the iliacus internally, were partially replaced by firm growth. The mesenteric, para-aortic, and cervical nodes were enlarged, firm and uniformly white, due to replacement by neoplasm.

There were two small cavities in the region of the right basal ganglia about $0.5 \mathrm{~cm}$. in diameter containing clear fluid.

All other organs appeared normal.

When the tumour nodules were microscopically examined they were all very similar, consisting of spindleshaped cells running in bundles, between which there were collagen fibres. The appearance was that of a fibrosarcoma.

There was no evidence of rheumatic infection of the heart, and the basal ganglia cavities seemed to be long standing developmental cysts. There was no evidence of chronic venous congestion. No tumour emboli or ante-mortem thrombi could be found in the vessels of the brain.

\section{Discussion}

The diagnosis of heart tumours during life is difficult, but certain features aiding ante-mortem recognition have been discussed at length by Yater (1931). A perusal of the literature seems to indicate that the important criteria for considering the diagnosis are intractable cardiac failure with no obvious cause; inconstant cardiac arrhythmias, e.g. heart block; evidence of valvular lesions influenced by posture; rare stenotic lesions, viz. tricuspid stenosis and acquired pulmonary stenosis; haemorrhagic pericardial effusion; evidence of obstruction to the major thoracic vessels; of a tumour elsewhere with cardiac dysfunction; unusual cardiac configuration on cardioscopy; and, in children, the presence of associated developmental abnormalities in a suspect case, particularly tuberose sclerosis.
Not many of these features may be expected in one case and bizarre combinations occur (Mahaim, 1945). In the child under discussion the combination of superior vena caval block, wasting, late pericardial friction rub, cardiomegaly, persistent tachycardia, and a changing systolic murmur with evidence of bone tumours, in retrospect suggested the correct diagnosis.

In this case it is difficult to be sure whether the heart tumour was primary or secondary. On the unreliable criterion of size it was primary. As sarcoma of bone rarely metastasizes to other bones, the multiple skeletal involvement in this case also suggested the heart as the primary site. The onset with a painful limp, however, might indicate that the primary tumour was in the right ilium which was the next largest tumour mass.

With such a large mass encroaching on the left auricle and mitral orifice, it is remarkable that there were no signs of congestive heart failure or mitral lesion during life. However, other observers have commented upon the surprising size reached by some cardiac tumours before obvious signs develop (Reisinger, Pekin, and Blumenthal, 1942). The E.C.G. finding in this case is understandable, as no deposits were found in any situation likely to affect the conducting system, and the deposits in the ventricles were relatively small.

It is difficult to explain the involuntary movements that were so prominent a feature throughout the illness. The cysts were considered on microscopic evidence to be developmental, and not embolic softenings as might be expected in view of the roughened surface of the main tumour.

\section{Summary}

A case of fibrosarcoma of the heart, probably primary, with involvement of bones, lung, and other organs is described in a child aged 3.

We wish to thank Professor A. G. Watkins and Professor J. Gough for their helpful criticism and advice.

We are also indebted to Mr. H. A. Griffiths for the photograph.

\section{REFERENCES}

Beck, C. S. (1942). Ann. Surg., 116, 161.

Lisa, J. R., Hirschhorn, L., and Hart, C. A. (1941). Arch. intern. Med., 67, 91.

Mahaim, I. (1945). 'Les Tumeurs et les Polypes du Coeur.' Paris.

Reisinger, J. A., Pekin, T. J., and Blumenthal, B. (1942). Ann. intern. Med., 17, 995.

Yater, W. M. (1931). Arch. intern. Med., 48, 627. 